\title{
A Mathematical Model For Analyzing And Employing Static And Dynamic Forces For A 50 Meter Freestyle Starting Position
}

\section{Dr.khaled abd el-mowgoud abd elazeem}

abstract: The study aimed to build a mathematical model to conduct a static and dynamic force analysis of the starting position in a 50-meter freestyle for [4] swimmers .In order to unveil the truth of what the lines of reaction force foot do during the stance and push phases, and then calculate the resultant of that force to rule the extent of the player's ability to employ an action line, of the resultant of the force of the foot towards the center of gravity, and at the same time the researcher tries to calculate the optimum take-off angle in theoretically by drawing a mathematical relationship between the take-off angle and the maximum horizontal distance while verifying the validity of the mathematical model, through the practical application of the model and a comparison between the results of the traditional take-off angle and the optimum take-off angle.

Keywords: static and dynamic force ; lines of reaction force ; optimum angle take-off

\section{Introduction: -}

Fractions of a second often separated the winner rest in high level races. In Freestyle races of 50 meters in length, the end times between the first and the third swimmer are only 0.09 seconds (males) and 0.05 seconds (females).[1][12]

The studies indicated that Starts account for approximately $10 \%$ of total time in swimming events of $50 \mathrm{~m}$ and for approximately $5 \%$ in those of $100 \mathrm{~m}$ race. Moreover, a strong start reduces race times by at least 0.1 seconds from the total race time. Thus, improving starting times may not only improve swimmer race time, but also improve race rankings [2 -1][6-57:62][7-10:113].

Which prompted the International Swimming Federation (FINA) in 2010 to change its facility regulations to allow starting blocks to back plates at international tournaments, which are now used at important domestic tournaments in Japan.[3-386]

In 2018, a study was conducted in which 21 swimmers have been test [11 men, 10 women], it has been found that post-start block time through $15 \mathrm{~m}$ was shorter with kick starts than with conventional track starts without a back plate. The mechanical factors associated with this were a high horizontal velocity at take-off and short block time.[3-386]

Several studies have been published, such as [Takeda, Takagi \& Tsubakimoto. 2009] [3], [Ozeki et al., 2014] [4] and [Nikodelis T, Kollias H 2003] [8], which aim to make comparisons between the new Start technique. from above the track start with the backrest (kick plate) and the traditional starting block, which it indicated that there are no statistically significant differences between them in the horizontal velocity at take-off and the total time of performance.

While a study by[Blanks by B, Nicholson L, Elliott B] [9] indicated that the horizontal velocity at take-off of the modern starting block is about 5 meters faster when the swimmer tilts forward over the starting block, but that feature is lost if the swimmer tilts back.

Other studies, such [Kruger T, et. Al.] [10], also indicated that there are differences in the push properties between the track start and the kick plate, and the starting block, where the highest amount of push at the beginning of the push phase is in the favor of the traditional starting block, but the modern track start with the backrest showed the highest amount of push at the end of the push phase, which is the moment of disposal of the starting block, 
although there was no significant difference in the time of push or in the horizontal velocity at take-off of both methods, as research indicates a difference in the efficiency of the starting technique, it depends on the individual efficiency of the swimmer.

Hence, the starting phase of swimming should be analyzed in more detail in order to determine the sub-phases within the beginning that have the greatest impact on the total start time. [11-16]

The first axis: a study and analysis of the static forces of the stance phase over the starting block: In light of some mechanical variables that control the position of the stance position for the starting skill of the track start in a $50 \mathrm{~m}$ freestyle swimming, in this aspect the researcher will impose a mechanical model to study the static side of the placement of the fulcrum, where the action forces are analyzed, which is the body weight, the earth's gravitational wheel, and the perpendicular reaction forces on the surface of the starting block. The researcher will also attempt, through an analysis of those forces as factors, and using the properties of parallelogram to find the resultant of two forces operating on an inclined surface with the horizontal by $\left[10^{\circ}\right]$ And old Rear (kick plate) tends to start with the surface of the start block at an angle [30 ${ }^{\circ}$, in order to determine the ability of the player to guide the resultant of forces the center of gravity, through the resultant of forces near or distance from the center of gravity [C.G].

The second axis: the study and analysis of the dynamic forces of the push phase of the starting block: the mathematical model will depend on that actual values of the quantities of the reaction forces of the foot during the push of the starting block, so the researcher will rely on an engineering model of the term force measurement platform that is flexible and consists of [hard ware, software] equipped with sensors to measure the reaction forces of the foot, which is characterized by a high accuracy in terms of measuring the amounts of variable forces at the least possible time, which is designed by the researcher, then formulating those values in the form of a mathematical model in order to analyze the forces exerted from the left and right foot, After measuring the amount made for each of them, drawing a two- forces action line, then finding the resultant of them and determining the direction of the effect affecting the center of gravity, taking into consideration the of take-off angle inclination, which is estimated $\left(10^{\circ}\right)$ inclination with the horizontal. The model aims at that phase to know how it is possible to maintain the amounts of Forces with the employing and directing of the resultant of the reaction forces towards the center of gravity and benefit from it after finding the optimum starting angle to obtain the maximum possible horizontal distance in light of the player's physical capabilities. as the researcher believes that the ability of the player to direct the force at the optimal angle is better than increasing the amount of force without directing.

The third axis: the study of the body in the starting phase as a projectile from the starting block: there are two types of starting block - track start. In this regard, several studies were conducted aimed at comparing the two types in the light of the physical controls that govern the performance, such as [horizontal distance ; time take - off angle of take - off deg ; angle of entry deg ; momentum ]. With regard to the entry angle deg, the entry circle must be small in proportion to the swimmer's body diameter, previously, specifically in the 1952 Olympics, the player was exposing the entire body to the surface of the water at the moment when the body met the water after jumping and that method makes expansion for the surface of the water, because the water consists of molecules connected to each other fig [1]. Never the less, the molecules on the surface of the water are not bonded from above, so at the moments when the surface of the swimmer's entire body is exposed to the surface of the water, the water surface molecules become more solid. The reason for is the occurrence of correlation between the surface of the water molecules from the above with the water 
molecules from the bottom. According to the third law of Newton, "for every action, there is an equal and opposite reaction." as, the player is exposed to high reaction forces in the direction of the opposite reaction from the surface of the water, so he must minimize the circle of entry into the water to avoid the opposite reaction forces. At the same time, the starting technique must be that he does not take the jump vertically and try to enter the water because that will make the swimmer dive deeper run smoothly. As the water forms a high resistance, and this has a negative effect on the time variable. Therefore, the direction of movement should be in view of employing the resultant force of the thrust towards the optimum angle take-off deg that achieves the largest possible horizontal distance what disables the swimmer dive or expose the entire surface of the body to the surface of the water. The researcher will try to find the optimum angle take-off deg and to calculate that, the mat lab program, one of the engineering and mathematical applications, will be used with the aim of drawing the relationship between the angle take-off deg which will be confined between $\left[6^{\circ}\right.$ to $\left.45^{\circ}\right]$ and the maximum horizontal distance that the player can achieve as a projectile. Through $\mathrm{f}$ the maximum horizontal distance achieved by the body, the researcher can infer the optimum take -off angle deg .

The researcher believes that understanding and studying the physical aspect of the starting position and take-off will help to unveil the reality of what mechanical laws do to reach the points of weakness and strength and then improve the starting position and take-off
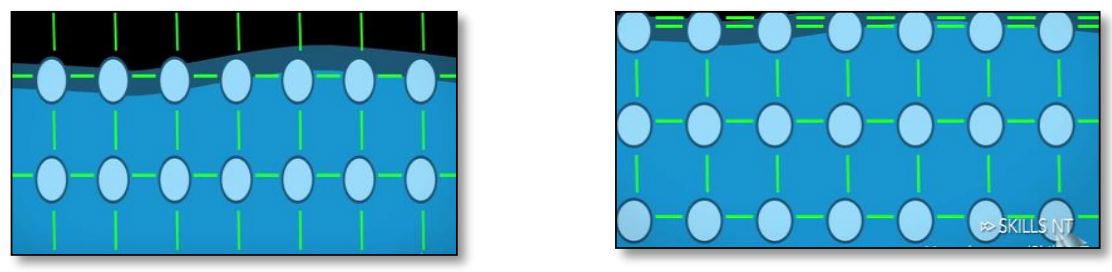

\section{Search aim: -}

fig[1] Interconnected water molecules

The research aims to build a "mathematical model for analyzing and employing static and dynamic forces for a starting position in a $50 \mathrm{~m}$ freestyle" by identifying:

- The optimum angle take-off in view of the mathematical relationship between the angle take-off and the maximum horizontal distance achieved by the swimmer body?

- The extent to which the resultant of the static and dynamic forces (stance - push) is used with the location of the center of gravity for the traditional and optimal take-off

\section{Search questions:-} angle for the starting position in the $50 \mathrm{~m}$ freestyle?

- What is The optimum angle take-off in view of the mathematical relationship between the angle take-off and the maximum horizontal distance achieved by the swimmer body?

- What is the extent to which the resultant of the static and dynamic forces (stance push) is used with the location of the center of gravity for the traditional and optimal Search procedures :take-off angle for the starting position in the $50 \mathrm{~m}$ freestyle?

\section{Research Methodology :}

The researcher used the descriptive approach (case study) due to its relevance to the nature and treatment of the research problem .The approach is concerned with describing the studied phenomenon in an accurate manner, using a quantitatively or qualitatively. The quantitative method gives a numerical description that clarifies this phenomenon and shows the degree of its association with other phenomena. 


\section{research community:}

The research community included assiut sports club swimmers, registered in the assiut swimming Branch records, the competence of $50 \mathrm{~m}$ freestyle, for the 2019/2020 training season, for the age level above [19] years and numbered [52] swimmer.

\section{The research sample :}

The research sample was chosen intentionally from the swimmers of the assiut sports club "Assiut Swimming Branch" which represented in Four public swimmers, men born in 2001. They are considered to have excellence in the technical performance (technical characteristics) of the skill under discussion, and they are the players who obtained advanced positions in the race of $50 \mathrm{~m}$ freestyle.

\section{Statistical characterization of the research sample:}

The researcher conducted special measurements uniformly to find torsional and flatness coefficients of the research sample individuals before conducting the experiment practical applications. This has been done in order to indicate the homogeneity of the members of the research sample to ensure moderation in the search variables that may affect the results of the application, and came as follows:

\section{Table [1]}

Average, standard deviation, coefficient of skewness and flatness of the variable (age, length, weight, Training age) of the sample in question. $\mathrm{N}$ [4]

\begin{tabular}{c|c|c|c|c|c|c}
\hline $\mathbf{N}$ & variables & M. unit & average & St .dev & Co.To & flatness \\
\hline 1 & Age & Year & 19.7 & $\pm \mathbf{0 . 8 3}$ & $\mathbf{0 . 8 5}$ & $-\mathbf{1 . 2 9}$ \\
\hline 2 & height & M / Cm & 1.74 & $\pm \mathbf{0 . 0 3}$ & $\mathbf{- 0 . 8 8}$ & $\mathbf{1 . 9 3}$ \\
\hline 3 & weight & Kg & 77 & \pm 2.39 & $\mathbf{0 . 3 2}$ & $\mathbf{- 3 . 0 3}$ \\
\hline 4 & Training age & year & 13.2 & $\pm \mathbf{0 . 8 3}$ & $\mathbf{- 0 . 8 5}$ & $\mathbf{- 1 . 2 9}$ \\
\hline
\end{tabular}

Table [1] shows that the value of the skewness coefficient varies between [$0.85: 0.85$,] which is less than the double of the standard error of the torsion coefficient. The value of the Kurt coefficient ranged between [- 3.03:1.93]، which is less than the double of the standard error of the Flatulence coefficient, which indicates the moderate distribution of the sample.

\section{Data collection devices and tools:-}

- The force platform designed by the researcher [attached].

- Program [mat lab V 2016].

- K Won 3D software.

- Digital camera [Basler] with a - DLT Calibration with dimensions frequency of $[120$ per $/ \mathrm{sec}]$.

of $2 \mathrm{~m} \times 2 \mathrm{~m}$, Fig [2].

- A tripod with a water scale.

- Marker, medical duct tape.

- A medical scale for measuring - Rest meter for length weight [k.g].

- Stop Watch. measurement [c.m].

- Swimming pool.

\section{- Start block}

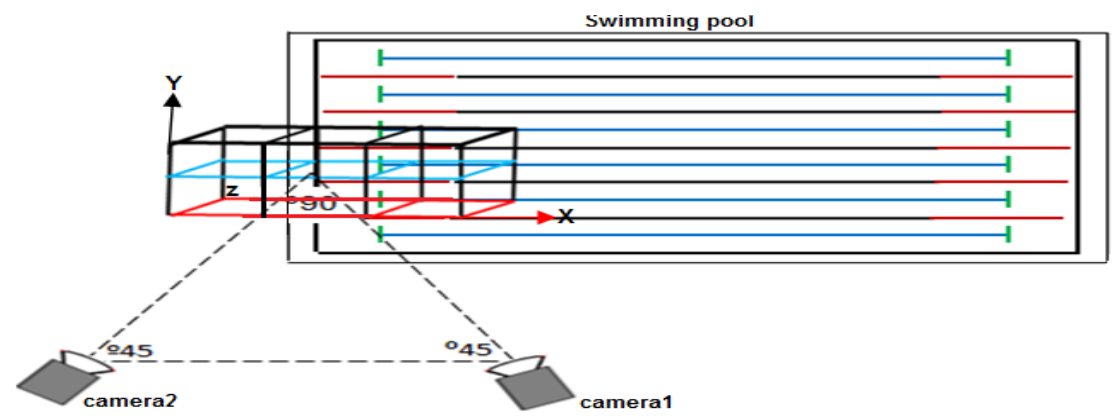

Fig [2] The position of the cameras and the DLT calibration followed during filming of the starting position and take-off 


\section{Statistical treatments:}

- Average

- standard deviation

- coefficient of torsion

- Flatness - percentage

\section{Method of building the proposed mathematical model :-}

The researcher divided the starting position in swimming into three basic phases which are (the fulcrum phase), in which the body is subjected to only one force, which is the gravitational force, then the propulsion phase until the moment the foot get rid of the starting block, finally the flight phase until the beginning of touching the fingers with the surface water, in which the body has become rejected).

\section{First: the phase of analyzing the static forces of the starting position:}

Fig [3] shows the analysis of the forces of the stance, which are a body weight carried on the foot, perpendicular to the starting block plane, and an attempt to find out the extent to which the player uses these forces through the proximity remoteness of the resultant of the forces of the foot from the center of gravity, accordingly the researcher took a number of mathematical steps, which show the construction of the mathematical model for the fulcrum phase: -

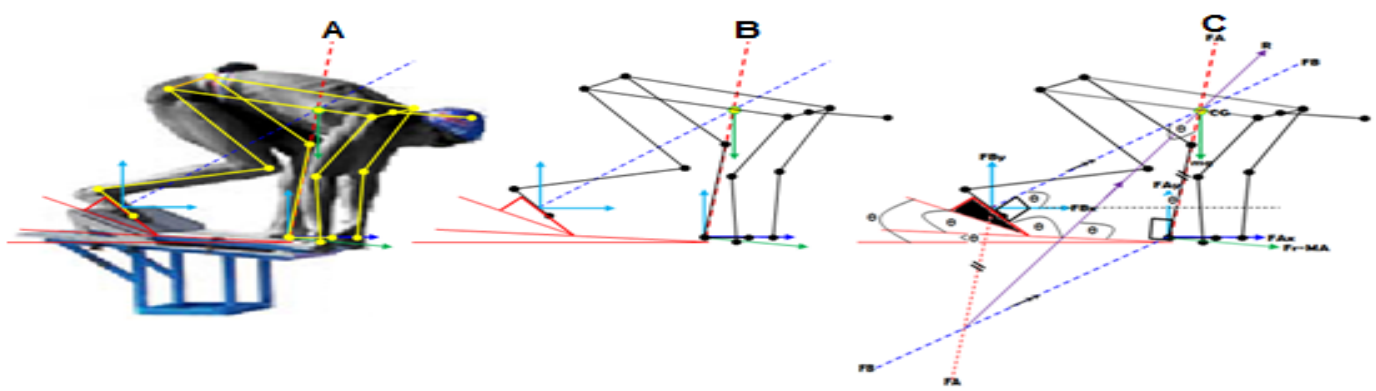

Fig [3] Static forces analysis of starting position, fulcrum phase

Table [1]

Translate the symbols used in the mathematical model

\begin{tabular}{|c|c|c|c|c|c|}
\hline $\mathbf{N}$ & SYM & Definition & $\mathbf{N}$ & SYM & Definition \\
\hline 1 & FA & Vertical force action line for the front foot & 9 & $\theta_{2}$ & $\begin{array}{l}\text { Angle resultant of the forces } \\
\text { with starting block }\end{array}$ \\
\hline 2 & FB & Vertical force action line for the rear foot & $\mathbf{1 0}$ & $\theta_{3}$ & $\begin{array}{c}\text { The kick plate angle with the } \\
\text { starting block }\end{array}$ \\
\hline 3 & $\mathbf{F A x}$ & The horizontal force of the front foot & 11 & $\theta_{4}$ & $\begin{array}{l}\text { Angle of horizontal force of the } \\
\text { rear foot }\end{array}$ \\
\hline 4 & FAy & The vertical force of the front foot & 12 & $\theta_{5}$ & $\begin{array}{l}\text { The angle of the vertical force } \\
\text { of the front foot }\end{array}$ \\
\hline 5 & FBx & The horizontal force of the rear foot & 13 & $\theta_{6}$ & $\begin{array}{c}\text { Angle of inclination of the start } \\
\text { block with the horizontal }\end{array}$ \\
\hline 6 & FBy & The vertical force of the rear foot & 14 & $\theta_{7}$ & $\begin{array}{l}\text { Angle of inclination of the start } \\
\text { block }\end{array}$ \\
\hline 7 & $\mathbf{R}$ & The resultant of the forces of the foot & 15 & M & friction \\
\hline 8 & $\theta_{1}$ & The angle resultant of the forces & 16 & $\mathbf{F r}$ & Friction force \\
\hline
\end{tabular}

Fig.[3] shows how static forces were analyzed according to their characteristics in terms of impact point, value, and direction. The effect point of the force represented in the front and back stance foot based on the starting position that the swimmer takes in view of the engineering design of the starting block, which takes a degree of inclination with the horizontal $10^{\circ}$. The force of each foot was analyzed separately, in the horizontal and vertical levels (XY).Also Friction force was analyzed for the front foot only, neglecting the friction force of the rear foot because it was perpendicular to the kick plate. 


\section{[1].Calculate the angle (o1) of the resultant of two forces [FA], [FB]:}

The swimmer's body in the starting position with the surface of the inclined starting cubic angle $10^{\circ}$ with the horizontally makes quadrilateral geometric form. As the figure shows two forces, which are the force [FA] of the front foot and the force [FB] of the rear foot, they are perpendicular to the starting bloke where each force creates an angle of $90^{\circ}$ with the starting bloke. It is known that the angles of the quadrilateral are equal to $360^{\circ}$, and by subtracting $360^{\circ}$ from the two existing angles which are $180^{\circ}, 180^{\circ}$, remains. According to the quadrilateral, the backrest restraint creates a $30^{\circ}$ angle with the starting bloke plane, so we conclude from this that the angle $\left[\theta_{3}\right]$ equals $150^{\circ}$, then the angle resultant of the force's is $\left[\theta_{1}\right]$ equal to $30^{\circ}$ and by adding the angles of the quadrilateral $=90^{\circ}+90^{\circ}+150^{\circ}+30^{\circ}=$ $360^{\circ}$.

[2]. Calculate the angle of inclination of the rear foot force with the horizontal plane $[\mathbf{F B x}]\left[\theta_{4}\right]$ :

The thrust angle was found by drawing a line parallel to the horizontal surface from the horizontal axis of the rear foot, as the thrust angle with the rear foot vertical force line $[\mathrm{FBx}]$ perpendicular to the starting bloke flat $60^{\circ}$, for being equitable to the angle.

\section{[3].Calculation of the resultant of two forces [R]:}

In order to draw a line resultant of two forces, the researcher followed the conditions of the vectors in calculating the results of two forces in view of the properties of the parallelogram, it follows one of the laws of mechanics, which states that: "If two forces work at a point, they can be expressed by one force." This force is called " resultant ". The output line of the two forces is exited from the angle of the action resultant to the angle of the reaction resultant, which is the angle $\left[\theta_{1}\right]$, Then the angle resultant of the force $[R]$ was calculated, according to Fig, [3] it is clear to us that there is a triangle, and it is known that the angles of the triangle $=180^{\circ}$ and the triangle has a right angle to the action line of the front foot force. Due to the half-line of the angular resultant of the force $\left[\theta_{1}\right]$, it becomes $\left[\theta_{1}\right]$ $=15^{\circ}$. According to the rule that indicates (the angle outside the triangle from one side $=$ the sum of the two inner angles of the triangle except for the adjacent to them . So the angle resultant of the force $=\theta_{2}+90+15=180$ if $\theta_{2}=75^{\circ}$.

\section{Second : Dynamic forces analysis phase for push and take-off position:-}

In the second phase, the researcher will analyze the dynamic forces at the moment of pushing and take-off at the horizontal plane $[\mathrm{X}]$ and the vertical plane $[\mathrm{Y}]$, which is the force exerted from the front and rear foot according to the starting position .The researcher will consider the actual amounts of the forces of pushing the foot from sensor specially designed by the researcher, which are placed under the front and front foot. In order to know the extent to which the player uses the resultant of these forces through the proximity or remoteness of the resultant from the center of gravity, so the researcher made a number of mathematical steps that show the construction of the mathematical model for the thrust and take-off phase and a fig [4] shows this.

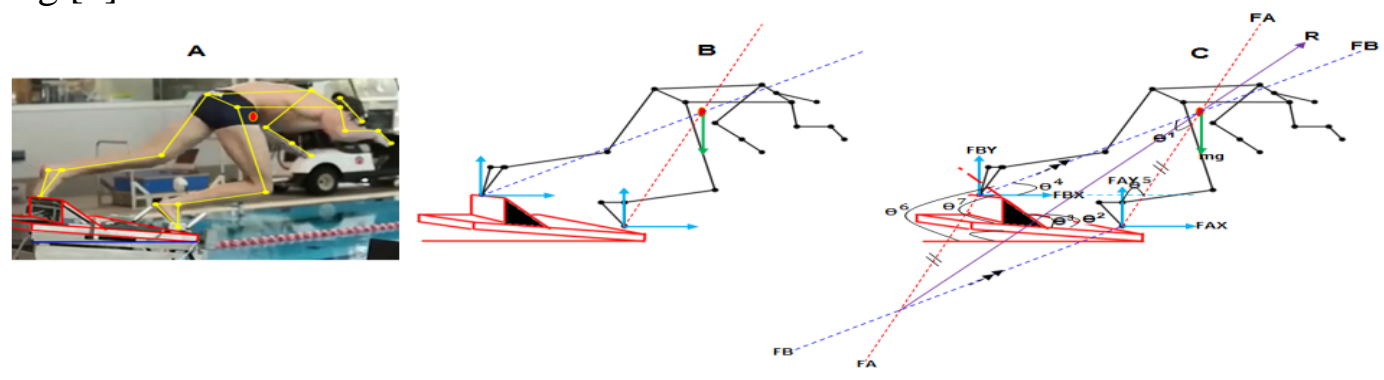

Fig [4] analysis of the dynamic forces of the take-off phase 
Fig [4]. Shows the analysis of the dynamic forces of the push phase before the foot got rid of the starting bloke, as the researcher took into account the force properties in terms of the point of influence, values, and direction. The force impact point is considered in the front and rear anchor foot, based on the push technique as shown in Figure (4). The force of each foot is analyzed separately at the horizontal and vertical plane (X.Y), and the frictional force of the front foot is analyzed only with neglecting the force of the rear foot friction for being perpendicular to the rear foot rest.

Table [2]

Mathematical equations for static and dynamic forces analysis

\begin{tabular}{c|c|c}
\hline $\mathbf{N}$ & equations & Definition \\
\hline $\mathbf{E q} \cdot \mathbf{1}$ & $F_{x}=F_{A} \sin \boldsymbol{\theta}+F_{B} \cos \boldsymbol{\theta}=\mathbf{0}$ & Calculate the horizontal force \\
\hline $\mathbf{E q} \cdot \mathbf{2}$ & $F_{y}=F_{A} \cos \boldsymbol{\theta}+F_{B} \sin \boldsymbol{\theta}-\mathbf{m g}=\mathbf{0}$ & Calculate the vertical force \\
\hline $\mathbf{E q} \cdot \mathbf{3}$ & $\mathbf{R}=\sqrt{F_{A}^{2}}+F_{B}^{2}+2 F_{A} F_{B} \cos \boldsymbol{\theta}$ & Calculation of the force resultant \\
\hline $\mathbf{E q} \cdot \mathbf{4}$ & $\mathbf{\Phi}=\tan ^{-1} \frac{F_{B} \sin \theta}{F_{A}+F_{B} \cos \theta}$ & Calculate the trend of the resultant \\
\hline
\end{tabular}

\section{Third: The stage of finding the optimum take-off angle:}

It is known that there is a relationship between the horizontal distance of the projectile and the take-off angle, according to this, the researcher has found the optimum angle take-off by the maximum horizontal distance achieved by the projectile with the stability of the initial velocity of the departure. In order to achieve this, the researcher used some mathematical equations to calculate the maximum horizontal distance up to the optimum angle take-off as follows: -

$$
\begin{array}{cc}
\text { Eq . } 5 & R_{\max }=\frac{u^{2}}{g(1+\sin \beta)} \\
\text { Eq . } 6 & \mathrm{R}=\sqrt{R_{\max ^{2}-(0.5)}} \\
\text { Eq. } 7 & {[\sin (2 \mathrm{a}-\beta)-\sin \beta] \mathrm{R}^{\prime}=\frac{u^{2}}{g \cos ^{2} \beta}} \\
\text { Eq. } 8 & {[\sin (2 \mathrm{a}-3 \beta)-\sin \beta] \mathrm{R}^{\prime}=\frac{u^{2}}{g \cos ^{2} \quad \beta}}
\end{array}
$$

The researcher entered equation No. [8] in the mat lab program, aiming to draw the indicated relationship between the take-off angle, that has been limited between $\left[6^{\circ}\right.$ to $\left.45^{\circ}\right]$, and the horizontal distance achieved by the player as a projectile, to find the optimal angle, in view of the maximum distance horizontal as a basic criterion for knowing the optimal angle fig [5].
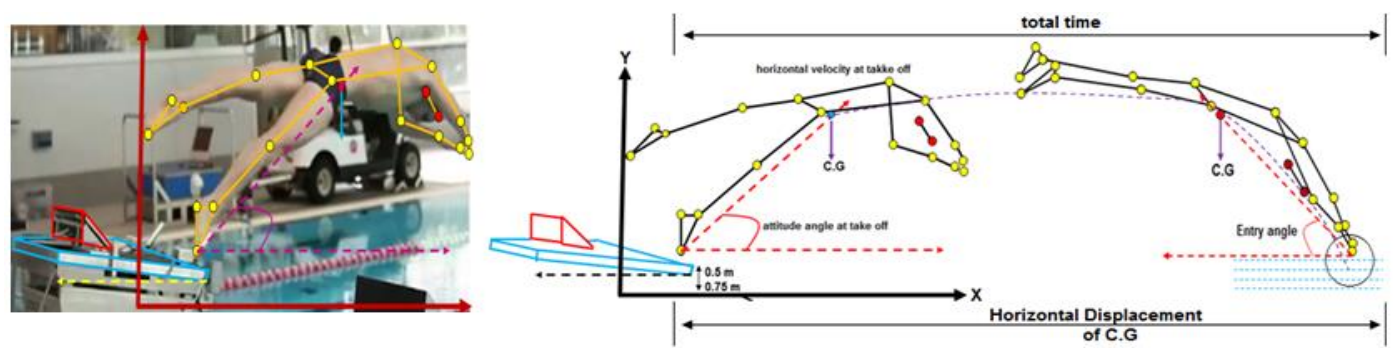

Fig [5] The take-off angle and optimum entry angle 


\section{Presentation and discussion of results:-}

The first question indicates: What is The optimum take-off angle in view of the mathematical relationship between the angle take-off and the maximum horizontal distance achieved by the Swimmer body?

The researcher calculated theoretical values based on the mathematical relationship between the take-off angle and the total horizontal distance achieved by the body, relying on this on the (V 2016 mat lab) program .which is one of the mathematical applications. The researcher could draw that theoretical relationship, assuming that the player's take-off velocity from the starting bloke is equal to $5 \mathrm{~m} / \mathrm{s}$ to find the optimum angle take-off by inferring the maximum horizontal distance that can be achieved in Table [3], Figure [6].

\section{Table [3]}

Theoretical values according to the mathematical relationship between the take-off angle and the maximum horizontal distance to calculate the optimum take-off angle.

\begin{tabular}{|c|c|c|c|c|c|c|c|c|c|}
\hline $\begin{array}{l}\text { Angle } \\
\text { [Deg] }\end{array}$ & $\begin{array}{c}\text { Distan } \\
\text { [m] }\end{array}$ & $\begin{array}{l}\text { Angle } \\
\text { [Deg] }\end{array}$ & $\begin{array}{c}\text { Distan } \\
\text { [m] }\end{array}$ & $\begin{array}{l}\text { Angle } \\
\text { [Deg] }\end{array}$ & $\begin{array}{l}\text { Distan } \\
\text { [m] }\end{array}$ & $\begin{array}{l}\text { Angle } \\
\text { [Deg] }\end{array}$ & $\begin{array}{c}\text { Distan } \\
{[\mathrm{m}]}\end{array}$ & $\begin{array}{l}\text { Angle } \\
\text { [Deg] }\end{array}$ & $\begin{array}{c}\text { Distan } \\
{[\mathrm{m}]}\end{array}$ \\
\hline $6^{\circ}$ & 2.217 & $14^{\circ}$ & 2.687 & $22^{\circ}$ & 2.985 & $30^{\circ}$ & 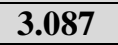 & $38^{\circ}$ & 2.985 \\
\hline $7^{\circ}$ & 2.284 & $15^{\circ}$ & 2.735 & $23^{\circ}$ & 3.009 & $31^{\circ}$ & $\mathbf{3 . 0 8 6}$ & $39^{\circ}$ & 2.958 \\
\hline $8^{\circ}$ & 2.349 & $16^{\circ}$ & 2.779 & $24^{\circ}$ & $\mathbf{3 . 0 3 0}$ & $32^{\circ}$ & 3.081 & $40^{\circ}$ & 2.929 \\
\hline $9^{\circ}$ & 2.412 & $17^{\circ}$ & 2.821 & $25^{\circ}$ & 3.047 & $\mathbf{3 3}^{\mathbf{o}}$ & 3.073 & $41^{\circ}$ & 2.896 \\
\hline $10^{\circ}$ & 2.472 & $18^{\circ}$ & 2.860 & $26^{\circ}$ & 3.062 & $34^{\circ}$ & 3.062 & $42^{\circ}$ & 2.860 \\
\hline $11^{\circ}$ & 2.530 & $19^{\circ}$ & 2.896 & $27^{\circ}$ & $\mathbf{3 . 0 7 3}$ & $35^{\circ}$ & $\mathbf{3 . 0 4 7}$ & $43^{\circ}$ & 2.821 \\
\hline $12^{\circ}$ & 2.585 & $20^{\circ}$ & 2.929 & $28^{\circ}$ & 3.081 & $36^{\circ}$ & 3.030 & $44^{\circ}$ & 2.779 \\
\hline $13^{\circ}$ & 2.637 & $21^{\circ}$ & 2.958 & $29^{\circ}$ & 3.086 & $37^{\circ}$ & 3.009 & $45^{\circ}$ & 2.730 \\
\hline
\end{tabular}

Table [3] shows the optimum take-off angle is $\left[30^{\circ}\right]$, in view of the maximum horizontal possible distance of $[3.087 \mathrm{~m}]$.

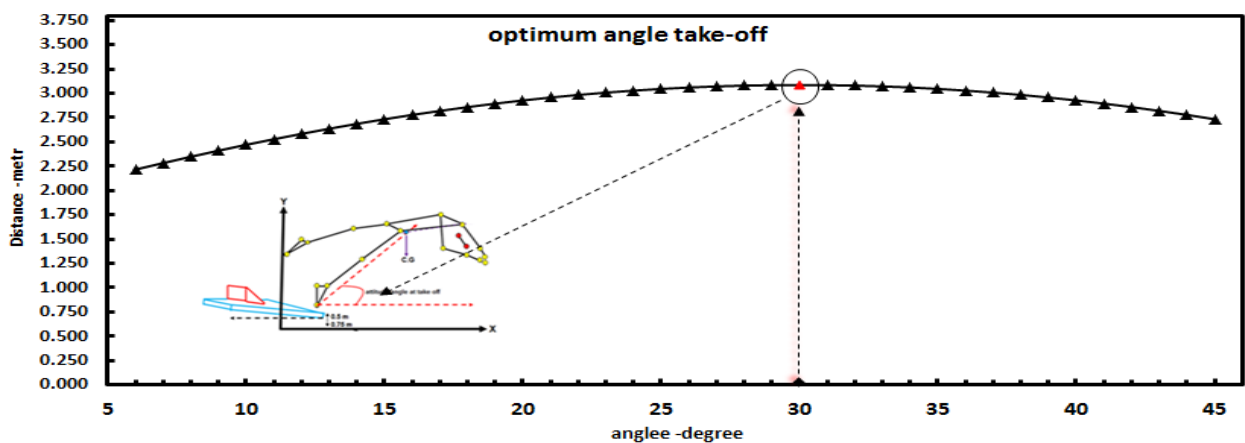

Fig [6] The optimum take-off angle curve

In view of the optimum take-off angle reached by the researcher using equation No. [8] which is $\left[30^{\circ}\right]$, the researcher conducted a practical application through the digital camera for the optimum take-off angle four swimmers to verify the results of the theoretical mathematical model with the mean of the traveled horizontal distance, [theoretical practical], Figure [7, 8] show the theoretical calculation and the practical application made by the researcher for the optimum take-off angle Then the researcher made a comparison between the achieved horizontal distance with the optimum take-off angle and the achieved distance with the traditional take-off angle, taking into account the initial starting velocity and table [4] showing the results of that comparison. 
Fig
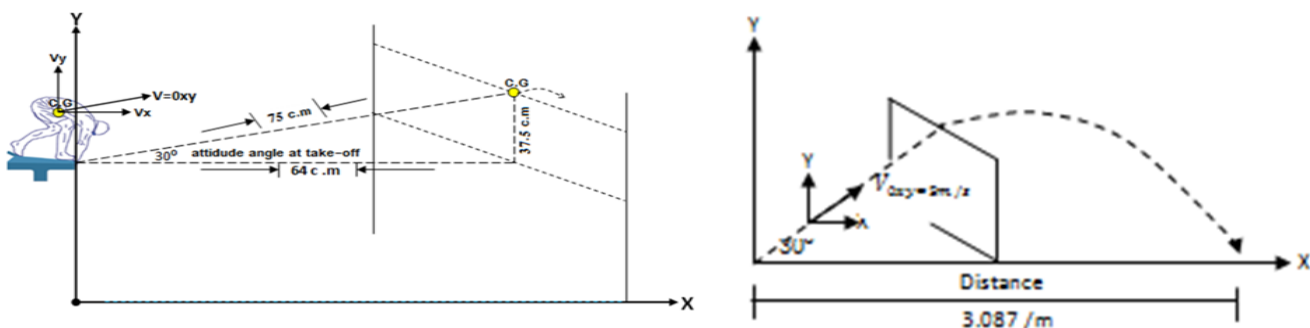

theoretical calculation of the optimum take-off angle
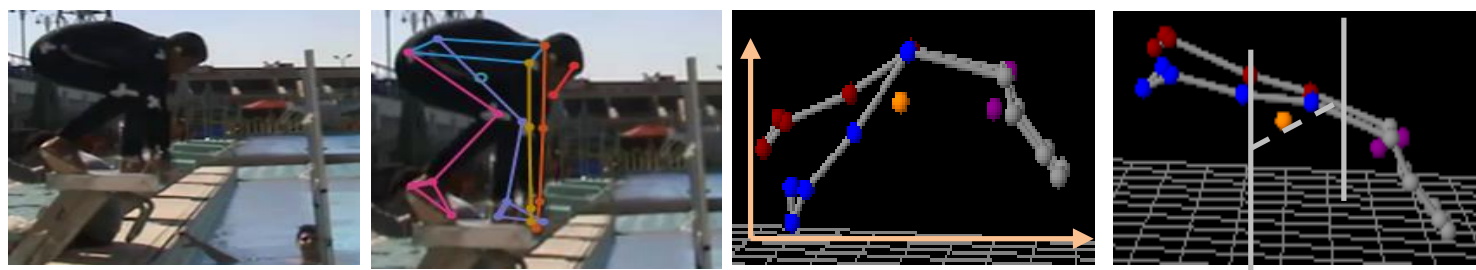

Figure [8] The practical application of the optimum take-off angle 


\section{Table [4]}

Maximum horizontal distance in view of optimum take-off angle and traditional angle $N=[4]$

Table [4] shows the quantitative differences and the percentage of shelter difference in the achieved horizontal distance for both the

\begin{tabular}{|c|c|c|c|c|c|c|c|c|c|}
\hline \multirow[b]{2}{*}{$\mathbf{N}$} & \multicolumn{4}{|c|}{$\begin{array}{l}\text { A comparison between the Optimum take-off angle (theoretical - } \\
\text { practical) }\end{array}$} & \multirow{2}{*}{$\begin{array}{c}\text { Enter } \\
\text { angle } \\
\text { [deg] }\end{array}$} & \multicolumn{3}{|c|}{$\begin{array}{l}\text { A comparison between the optimum take-off angle } \\
\text { and the traditional angle }\end{array}$} & \multirow{2}{*}{$\begin{array}{c}\text { Enter } \\
\text { angle [deg] }\end{array}$} \\
\hline & parameters & $\begin{array}{c}\text { V. take-off } \\
{[\mathrm{m} / \mathrm{s}]}\end{array}$ & $\begin{array}{c}\text { take-off } \\
\text { Angle [deg] }\end{array}$ & $\begin{array}{c}\text { Distance } \\
{[\mathrm{m}]}\end{array}$ & & $\begin{array}{c}\text { V. take-off } \\
{[\mathrm{m} / \mathrm{s}]}\end{array}$ & $\begin{array}{c}\text { take-off } \\
\text { Angle [deg] }\end{array}$ & $\begin{array}{c}\text { Distance } \\
{[\mathrm{m}]}\end{array}$ & \\
\hline \multirow{4}{*}{1} & The first player & 5.24 & $30^{\circ}$ & 3.39 & 32 & 5.5 & $41^{\circ}$ & 3.5 & $43^{\circ}$ \\
\hline & Mathematical model & 5.24 & $30^{\circ}$ & 3.41 & $30^{\circ}$ & 5.5 & $30^{\circ}$ & 3.74 & $35^{\circ}$ \\
\hline & difference & 0.00 & 0.00 & 0.02 & $2^{\circ}$ & 0.00 & $11^{\circ}$ & 0.24 & $8^{\circ}$ \\
\hline & Percentage difference & $\% 0.00$ & $\% 0.00$ & $0.58 \%$ & $\% 6.6$ & $\% 0.00$ & $\% 36.6$ & $\% 6.4$ & $\% 22.8$ \\
\hline \multirow{4}{*}{2} & The second player & 4.50 & $30^{\circ}$ & 2.48 & $33^{\circ}$ & 4.40 & $43^{\circ}$ & 2.18 & $47^{\circ}$ \\
\hline & Mathematical model & 4.50 & $30^{\circ}$ & 2.5 & $30^{\circ}$ & 4.40 & $30^{\circ}$ & 2.39 & $35^{\circ}$ \\
\hline & difference & 0.00 & 0.00 & 0.02 & $3^{\circ}$ & 0.00 & $13^{\circ}$ & 0.21 & $12^{\circ}$ \\
\hline & Percentage difference & $\% 0.00$ & $\% 0.00$ & $0.8 \%$ & $\% 10$ & $\% 0.00$ & $\% 43.3$ & $\% 8.78$ & $\% 35.28$ \\
\hline \multirow{4}{*}{3} & The third player & 4.35 & $30^{\circ}$ & 2.32 & $35^{\circ}$ & 4.40 & $45^{\circ}$ & 2.11 & $46^{\circ}$ \\
\hline & Mathematical model & 4.35 & $30^{\circ}$ & 2.33 & $30^{\circ}$ & 4.40 & $30^{\circ}$ & 2.39 & $35^{\circ}$ \\
\hline & difference & 0.00 & 0.00 & 0.01 & $5^{\circ}$ & 0.00 & $15^{\circ}$ & 0.28 & $11^{\circ}$ \\
\hline & Percentage difference & $\% 0.00$ & $\% 0.00$ & $0.42 \%$ & $16.6 \%$ & $\% 0.00$ & $50 \%$ & 11.7 & $\% 31.4$ \\
\hline \multirow{4}{*}{4} & The fourth player & 5.30 & $30^{\circ}$ & 3.44 & $32^{\circ}$ & 5.10 & $42^{\circ}$ & 2.97 & $45^{\circ}$ \\
\hline & Mathematical model & 5.30 & $30^{\circ}$ & 3.47 & $30^{\circ}$ & 5.10 & $30^{\circ}$ & 3.21 & $35^{\circ}$ \\
\hline & difference & 0.00 & 0.00 & 0.03 & $2^{\circ}$ & 0.00 & $12^{\circ}$ & 0.24 & $10^{\circ}$ \\
\hline & Percentage difference & $\% 0.00$ & $\% 0.00$ & $0.86 \%$ & $\% 6.6$ & $\% 0.00$ & $40 \%$ & 7.47 & $\% 28.57$ \\
\hline
\end{tabular}

traditional angle and the optimum take-off angle, by comparison between the practical application of the mathematical model and the player taking into account the take-off velocity. 
The first question aims to find the optimum take-off angle for the starting position in the 50-meter freestyle, by imposing a mathematical model under governing performance controls, which are the initial starting velocity, the height of the starting plane and the angle of inclination of the starting block with the horizontal plane, the nature of the starting position technique, based on the importance of the starting time and its effect on the overall time of the race. The researcher relied on an indicator of the maximum horizontal distance that can be achieved in view of the starting velocity in order to infer the optimal take-off angle, and to achieve so, the researcher follows two main axes.

The first axis is the theoretical application of the mathematical model using the program (V 2016 mat lab) with the aim of reaching the theoretical values of the take-off angle with drawing a mathematical relationship between the distance and the take-off angle, table (3) shows the theoretical values that the researcher reached for the different take-off angles, as the lowest take-off angle is $\left[6^{\circ}\right]$ is $\left[45^{\circ}\right]$, as well as the minimum horizontal distance is $[2.21 \mathrm{~m}]$ at the take-off angle $\left[6^{\circ}\right]$, While the maximum horizontal distance is $[3.087 \mathrm{~m}]$ reached at the take-off angle is $\left[30^{\circ}\right]$, the researcher drew a theoretical mathematical relationship between the angle take-off and the maximum horizontal distance and the form of [6] shows that relationship, so it is possible to infer the optimal take off angle which is the angle $\left[30^{\circ}\right]$.

What is known about ballistics theory that the most appropriate take-off angle gives the maximum horizontal distance is the angle $\left[45^{\circ}\right]$ due to the equality of forces at the horizontal and vertical plane, provided that the starting point level is equal to the plane of the landing point, that is, the angle shadow value $=1$. "The take-off angle is the angle between the path of the body's center of gravity and the horizontal line at the point of departure from the starting block." According to the starting point plane in the current study of the starting position is higher than the plane of the landing point which is the surface of the water where the starting bloke rises by $[0.75 \mathrm{~m}]$ Above the water plane, taking into account the angle of the inclination of the starting bloke with the horizontal plane, which is $\left[10^{\circ}\right]$. So the angle $\left[45^{\circ}\right]$ is not suitable here as the most appropriate angle of departure and according to this situation the angle of departure should be less than the angle $\left[45^{\circ}\right]$.

The second axis is the practical application of the optimum take-off angle to verify the validity of the mathematical model with respect to the optimum take-off angle that the researcher has reached, in which the researcher took into account the actual starting velocity, which was measured, then it was introduced to the mathematical model to ensure the stability of all variables with only the take-off angle test to reach the maximum achievable distance, where the table [4] shows the actual comparison values between the theoretical values of the mathematical model and both the traditional take-off angle and the optimum take-off angle for the number of [4] swimmers in the view of the maximum horizontal distance and the effect of the take-off angle on the entry angle of the water. According to the results of the application, the difference came in the maximum horizontal distance in the favor of the optimal angle $\left[30^{\circ}\right]$, so the difference in the horizontal distance between the optimum angle and the traditional take-off angle ranged between $\left[41^{\circ}: 45^{\circ}\right]$, and the horizontal distance difference ranged between $\left[28^{\circ} \mathrm{c} . \mathrm{m}: 21 \mathrm{c} . \mathrm{m}\right]$ with a shelter rate that ranged between $[8.78 \%: 11.7 \%]$. While the horizontal distance difference decreased between the practical application of the optimum take-off angle and the mathematical model as the distance difference ranged between $[0.03$ c. m: 0.01 c. m] 
with a percentage ranged between $[0.42 \% 0.86 \%]$ which is a very slight difference compared to the traditional take-off angle.

As a result of increasing the angle take-off the traditional take-off point ,the entry angle of the player into the water has increased, as the entry angle of the water ranged between $\left[43^{\circ}: 47^{\circ}\right]$ with the horizontal plane by a difference between $\left[8^{\circ}: 12^{\circ}\right]$ from the optimum take-off angle. The researcher believes that the starting technique should not be jumping vertically and then trying to enter the water because this will increase the entry angle of the water with the horizontal plane, which makes the swimmer dive into the depth without flowing. Hence the water forms a high resistance what results in a negative impact on time as a determiner of the race results. Therefore, the direction of movement must be in light of employing the resultant forces of the thrust towards the optimum take-off angle that the researcher reached and that achieves the maximum possible horizontal distance that does not make the swimmer dive or expose the entire body surface to the of the water surface.

Second: The second question indicates: What is the extent to which the resultant of the static and dynamic forces (fulcrum - push) is used with the location of the center of gravity for the traditional and optimal take-off angle for the starting position in the $50 \mathrm{~m}$ freestyle?

The researcher has taken several basic steps in analyzing the static and dynamic forces of the phase and the momentary thrust of the starting position in the 50 meter freestyle race during the player's departure from the traditional angle and the optimal angle, as follows: Draw the force action line for the right foot and the left foot according to the angle of inclination of the foot with the horizontal

- Find the angle of the force action line for the foot with the horizontal and vertical planes as the force vector.

- In static analysis, the player's body weight is analyzed as a measure of force.

- In the dynamic analysis the amount of force is measured from the force measure platform (researcher design)

- Analysis of force at the horizontal and vertical planes using equation [1], [2].

- Calculate the force resultant using equation [3].

- Calculate the direction of the two forces' resultant using equation [4].

- Calculating the angle of inclination of the center of gravity from the action line of the forces resultant to know the extent of employing of the force collector with the center of gravity.

Figure [9] shows how the practical mathematical analysis was performed, as well as a table [5] shows the results of the practical application of power analysis for [4] swimmers with a calculation of the inclination angle of the center of gravity from the direction of the forces resultant, aiming to show the player's ability to employ the force resultant with The center of gravity during the fulcrum and push phases of the starting position according to the take-off angle.

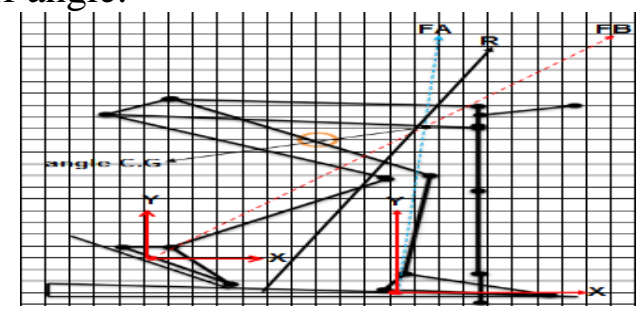

Fig[9] static analysis of force [practical]

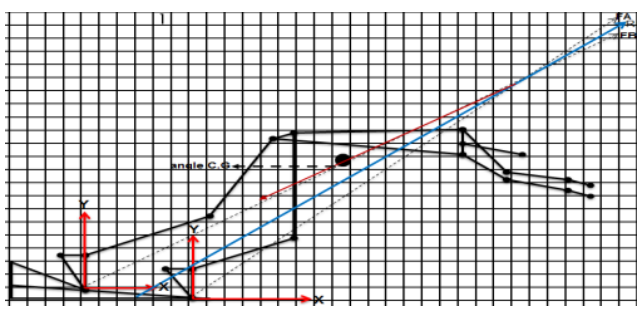

Fig [9] Dynamic force Analysis [practical] 
Table [5]

Results of applying the mathematical model to analyze the static and dynamic force of the (fulcrum - push) phase of the starting position, according to the traditional and optimum take-off angle $\mathrm{N}=[4]$

\begin{tabular}{|c|c|c|c|c|c|c|c|c|c|c|c|c|c|c|c|c|c|}
\hline $\mathrm{N}$ & Type of analysis & \multicolumn{7}{|c|}{ Static analysis of force, traditional take-off angle } & \multicolumn{7}{|c|}{ Dynamic analysis of force, traditional take-off angle } & \multicolumn{2}{|c|}{ Lost force } \\
\hline \multirow{9}{*}{$\frac{\grave{d}}{\stackrel{0}{a}}$} & foot & \multirow{2}{*}{\multicolumn{2}{|c|}{$\begin{array}{c}\text { R .foot } \\
51^{\circ} \\
\end{array}$}} & \multirow{2}{*}{\multicolumn{2}{|c|}{$\begin{array}{c}\text { L .foot } \\
87^{\circ} \\
\end{array}$}} & \multirow{3}{*}{$\begin{array}{c}\text { force } \\
\text { line } \\
\text { angle }\end{array}$} & \multirow{3}{*}{$\begin{array}{c}\text { Angle } \\
\text { of } \\
\text { resulta } \\
\text { nt }\end{array}$} & \multirow{3}{*}{$\begin{array}{c}\text { C.G } \\
\varnothing \\
\text { Deg }\end{array}$} & \multirow{2}{*}{\multicolumn{2}{|c|}{$\begin{array}{c}\text { R .foot } \\
40^{\circ} \\
\end{array}$}} & \multirow{2}{*}{\multicolumn{2}{|c|}{$\begin{array}{c}\text { L.foot } \\
51^{\circ} \\
\end{array}$}} & \multirow{3}{*}{$\begin{array}{l}\text { force } \\
\text { line } \\
\text { angle }\end{array}$} & \multirow{3}{*}{$\begin{array}{c}\text { Angle } \\
\text { of } \\
\text { resulta } \\
\text { nt }\end{array}$} & \multirow{3}{*}{$\begin{array}{c}\text { C.G } \\
\varnothing \\
\text { Deg }\end{array}$} & & \\
\hline & angle of inclination & & & & & & & & & & & & & & & & \\
\hline & Variables & $\mathbf{F x}[\mathbf{N}]$ & $\mathbf{F y}[\mathbf{N}]$ & $\mathbf{F x}[\mathbf{N}]$ & $\mathbf{F y}[\mathbf{N}]$ & & & & $\mathbf{F x}[\mathbf{N}]$ & $\mathbf{F y}[\mathbf{N}]$ & $\mathbf{F x}[\mathbf{N}]$ & $\mathbf{F y}[\mathbf{N}]$ & & & & L. $\mathbf{f}$ & R. f \\
\hline & Force values & 134.6 & 166.2 & 26.3 & 502 & $36^{\circ}$ & $10.5^{\circ}$ & $16^{\circ}$ & 202 & 170 & 277.8 & 343 & $11^{\circ}$ & $4.11^{\circ}$ & $8.5^{\circ}$ & 52.7 & 31.6 \\
\hline & Type of analysis & \multicolumn{7}{|c|}{ Static analysis of force, optimum take-off angle } & \multicolumn{7}{|c|}{ Dynamic analysis of force, optimum take-off angle } & & \\
\hline & angle of inclination & \multicolumn{2}{|c|}{$\mathbf{5 2 ^ { \circ }}$} & \multicolumn{2}{|c|}{$\mathbf{8 5}^{\mathbf{0}}$} & & & & \multicolumn{2}{|c|}{$37^{\circ}$} & \multicolumn{2}{|c|}{$\mathbf{4 3}^{\mathbf{0}}$} & & & & & \\
\hline & Force values & 131.6 & 168.5 & 43.82 & 500.8 & $33^{\circ}$ & $9.7^{\circ}$ & $10^{\circ}$ & 277 & 171 & 473 & 411 & $6^{\circ}$ & $1.9^{\circ}$ & $2.5^{\circ}$ & 22.1 & 11.2 \\
\hline & difference & -3 & 2.3 & 17.52 & -1.2 & $3^{\circ}$ & $-0.8^{\circ}$ & $6^{\circ}$ & 75 & 1 & 133.2 & 130 & -5 & $-2.21^{\circ}$ & $6^{\circ}$ & -30.6 & -20.4 \\
\hline & Percentage difference & $2.27 \%$ & $1.36 \%$ & $4 \%$ & $0.24 \%$ & $9 \%$ & $8.24 \%$ & $60 \%$ & $27 \%$ & $0.6 \%$ & $32.4 \%$ & $27.5 \%$ & $83.3 \%$ & $116 \%$ & & & \\
\hline \multirow{8}{*}{ 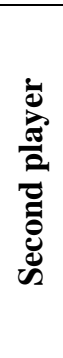 } & Type of analysis & \multicolumn{7}{|c|}{ Static analysis of force, traditional take-off angle } & \multicolumn{7}{|c|}{ Dynamic analysis of force, traditional take-off angle } & & \\
\hline & angle of inclination & \multicolumn{2}{|c|}{$59^{\circ}$} & \multicolumn{2}{|c|}{$87^{\circ}$} & & & & \multicolumn{2}{|c|}{$42^{\circ}$} & \multicolumn{2}{|c|}{$49^{\circ}$} & & & & & \\
\hline & Force values & 92.2 & 153.5 & 33 & 630 & $28^{\circ}$ & $6^{\circ}$ & $12^{\circ}$ & 111 & 96.5 & 205.9 & 236.9 & $7^{\circ}$ & $2.23^{\circ}$ & $6.7^{\circ}$ & 29.6 & 13.9 \\
\hline & Type of analysis & \multicolumn{7}{|c|}{ Static analysis of force, optimum take-off angle } & \multicolumn{7}{|c|}{ Dynamic analysis of force, optimum take-off angle } & & \\
\hline & angle of inclination & \multicolumn{2}{|c|}{$\mathbf{5 8}^{\mathbf{0}}$} & \multicolumn{2}{|c|}{$84^{\circ}$} & & & & & & & & & & & & \\
\hline & Force values & 89.7 & 143.6 & 67.00 & 637.5 & $26^{\circ}$ & $5.34^{\circ}$ & $8.5^{\circ}$ & 112.00 & 81.4 & 224.7 & 181.9 & $3^{\circ}$ & $1^{\circ}$ & $1.3^{\circ}$ & 5.2 & 2.5 \\
\hline & difference & -2.5 & -9.9 & 34 & 7.5 & -2 & -0.66 & $3.5^{\circ}$ & 1 & -15.1 & 18.8 & -55 & -4 & -1.23 & $5.4^{\circ}$ & -24.4 & -11.4 \\
\hline & Percentage difference & $2.8 \%$ & $6.9 \%$ & $50.7 \%$ & $1.2 \%$ & $7.7 \%$ & $12.4 \%$ & $41 \%$ & $0.9 \%$ & $18.6 \%$ & $8.4 \%$ & $30.2 \%$ & $133.3 \%$ & $123 \%$ & & & \\
\hline
\end{tabular}

Table [5] Shows the static analysis of the force represented in the body weight during the anchoring stage, the dynamic analysis of the reaction force during the fulcrum phase for both the traditional take-off and the optimum take-off angle, and the calculation of the force lost in view of the of inclination angle of the center of gravity from the resultant of action line for the first player and the second. 
Follow a table [5] Results of applying the mathematical model to analyze the static and dynamic force of the (fulcrum - push) phase of the starting position, according to the traditional and optimum take-off angle $N=[4]$

Table [5] Shows the static analysis of the force represented in the body weight during the anchoring stage, the dynamic analysis of the reaction force during the fulcrum phase for both the traditional take-off and the optimum take -off angle, and the calculation of the force lost in

\begin{tabular}{|c|c|c|c|c|c|c|c|c|c|c|c|c|c|c|c|c|c|}
\hline $\mathrm{N}$ & Type of analysis & \multicolumn{7}{|c|}{ Static analysis of force, traditional take-off angle } & \multicolumn{7}{|c|}{ Dynamic analysis of force, traditional take-off angle } & \multirow{2}{*}{\multicolumn{2}{|c|}{ Lost force }} \\
\hline \multirow{9}{*}{ 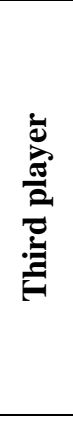 } & foot & \multirow{2}{*}{\multicolumn{2}{|c|}{$\frac{\text { R .foot }}{57^{\circ}}$}} & \multirow{2}{*}{\multicolumn{2}{|c|}{$\begin{array}{c}\text { L .foot } \\
\mathbf{8 8}^{\circ}\end{array}$}} & \multirow{3}{*}{$\begin{array}{c}\text { force } \\
\text { line } \\
\text { angle }\end{array}$} & \multirow{3}{*}{$\begin{array}{c}\text { Angle } \\
\text { of } \\
\text { resulta } \\
\text { nt }\end{array}$} & \multirow{3}{*}{$\begin{array}{c}\text { C.G Ø } \\
\text { Deg }\end{array}$} & \multirow{2}{*}{\multicolumn{2}{|c|}{$\begin{array}{c}\text { R .foot } \\
39^{\circ} \\
\end{array}$}} & \multirow{2}{*}{\multicolumn{2}{|c|}{$\begin{array}{c}\text { L .foot } \\
48^{\circ} \\
\end{array}$}} & \multirow{3}{*}{$\begin{array}{l}\text { force } \\
\text { line } \\
\text { angle }\end{array}$} & \multirow{3}{*}{$\begin{array}{c}\text { Angle } \\
\text { of } \\
\text { resulta } \\
\text { nt }\end{array}$} & \multirow{3}{*}{$\begin{array}{c}\text { C.G } \\
\varnothing \\
\text { Deg }\end{array}$} & & \\
\hline & angle of inclination & & & & & & & & & & & & & & & & \\
\hline & Variables & $\mathbf{F x}[\mathbf{N}]$ & $\mathbf{F y}[\mathbf{N}]$ & $\mathbf{F x}[\mathbf{X}]$ & $\begin{array}{c}\mathbf{F y}[\mathbf{N} \\
]\end{array}$ & & & & $\mathbf{F x}[\mathbf{N}]$ & $\mathbf{F y}[\mathbf{N}]$ & $\mathbf{F x}[\mathbf{X}]$ & $\mathbf{F y}[\mathbf{N}]$ & & & & L. $\mathbf{f}$ & R.f \\
\hline & Force values & 97 & 150.15 & 17 & 487.7 & $31^{\circ}$ & $8.1^{\circ}$ & $12.5^{\circ}$ & 177 & 143.5 & 308.5 & 342.6 & $9^{\circ}$ & $2.4^{\circ}$ & $7^{\circ}$ & 45.5 & 22.4 \\
\hline & Type of analysis & \multicolumn{7}{|c|}{ Static analysis of force, optimum take-off angle } & \multicolumn{7}{|c|}{ Dynamic analysis of force, optimum take-off angle } & & \\
\hline & angle of inclination & \multicolumn{2}{|c|}{$57^{\circ}$} & \multicolumn{2}{|c|}{$\mathbf{8 6}^{\mathbf{0}}$} & & & & \multicolumn{2}{|c|}{$\mathbf{3 0}^{\mathbf{6}}$} & \multicolumn{2}{|c|}{$\mathbf{0} 35$} & & & & & \\
\hline & Force values & 86.8 & 133.7 & 35.4 & 506.4 & $29^{\circ}$ & $6.8^{\circ}$ & $8^{\circ}$ & 133.2 & 78.00 & 435.00 & 303.8 & $5^{\circ}$ & $1.1^{\circ}$ & $2^{\circ}$ & 14.7 & 4.2 \\
\hline & difference & -10.2 & -16.45 & 18.4 & 18.7 & 25.9 & -1.3 & $4.5^{\circ}$ & -43.8 & -65.5 & 126.5 & -38.8 & -4 & -1.3 & $5^{\circ}$ & -10.2 & -18.2 \\
\hline & Percentage difference & $11.8 \%$ & $12.3 \%$ & $52 \%$ & $3.7 \%$ & $89.3 \%$ & $19 \%$ & $56.2 \%$ & $32.9 \%$ & $84 \%$ & $29 \%$ & $12.8 \%$ & $80 \%$ & $118.2 \%$ & & & \\
\hline \multirow{8}{*}{ 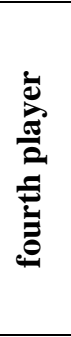 } & Type of analysis & \multicolumn{7}{|c|}{ Static analysis of force, traditional take-off angle } & \multicolumn{7}{|c|}{ Dynamic analysis of force, traditional take-off angle } & & \\
\hline & angle of inclination & \multicolumn{2}{|c|}{$\mathbf{5 8}^{\mathbf{0}}$} & \multicolumn{2}{|c|}{$87^{\circ}$} & & & & \multicolumn{2}{|c|}{$38^{\circ}$} & \multicolumn{2}{|c|}{$48^{\circ}$} & & & & & \\
\hline & Force values & 71.7 & 114.8 & 32.9 & 628.9 & $29^{\circ}$ & $5^{\circ}$ & 10.8 & 114.9 & 89.8 & 343.9 & 381.9 & $10^{\circ}$ & $2.2^{\circ}$ & $9^{\circ}$ & 65.3 & 18.4 \\
\hline & Type of analysis & \multicolumn{7}{|c|}{ Static analysis of force, optimum take-off angle } & \multicolumn{7}{|c|}{ Dynamic analysis of force, optimum take-off angle } & & \\
\hline & angle of inclination & \multicolumn{2}{|c|}{${ }^{\circ} 57$} & \multicolumn{2}{|c|}{${ }^{\circ} 85$} & & & & & & & & & & & & \\
\hline & Force values & 63.5 & 97.7 & 56.6 & 647.4 & $28^{\circ}$ & $4.13^{\circ}$ & $8^{\circ}$ & 122.3 & 79.4 & 376.5 & 305.00 & $6^{\circ}$ & $1.4^{\circ}$ & $1.7^{\circ}$ & 11.5 & 3.4 \\
\hline & difference & -8.2 & -17.1 & 23.7 & 18.5 & -1 & -0.87 & $2.8^{\circ}$ & 7.4 & -10.4 & 32.6 & -76.9 & -4 & -0.8 & $7.3^{\circ}$ & -53.8 & -15 \\
\hline & Percentage difference & $12.9 \%$ & $17.5 \%$ & $41.9 \%$ & $2.9 \%$ & $3.6 \%$ & $21.2 \%$ & $31.2 \%$ & $6.1 \%$ & $13.1 \%$ & $8.7 \%$ & $25.2 \%$ & & & & & \\
\hline
\end{tabular}

view of the of inclination angle of the center of gravity from the resultant of action line for the first player and the fourth. 
Table [5] shows that the researcher was able to built the mathematical model and then analyzed the static and dynamic force of the stance and push phase of the starting position in the $50 \mathrm{~m}$ freestyle race. The table also shows the quantitative differences and the percentages for the forces at the horizontal plane $[\mathrm{X}]$ and the vertical plane [Y] between the traditional take-off angle and the optimum take-off angle, the researcher inculcates that those differences enable the player to employ the resultant work line of the right and left foot forces during the stance and push phases. The player's ability to employ the force line of the two forces towards the center of gravity is due to the player's exit from the optimum take-off angle of [30، ], which results in the small angle of the force line of each foot with the horizontal plane.

The results of static force analysis also show higher values for the forces at the vertical plane of the front and rear foot during the stance phase, According to the nature of the starting position technique, in which the body weight is semiperpendicular to the front foot as it makes with the horizontal plane a inclination angle that ranges from $\left[88^{\circ}: 8^{\circ}\right]$ during the launch from the traditional angle, and from [ 86 o: $\left.84^{\circ}\right]$ during the launch from the optimal angle. Also the rear foot creates a sharp wide angle with the horizontal plane which amount ranges from $\left[59^{\circ}: 51^{\circ}\right]$ during the departure from the traditional angle, and from [58 $\left.: 52^{\circ}\right]$ during starting from the optimum angle. Therefore researcher also noted that the of inclination angle of the center of gravity is greater than the action line of the forces resultant of the left foot and the right foot during the departure from the traditional angle where the of inclination angle of the center of gravity decreased from $\left[16^{\circ}: 10.8^{\circ}\right]$, while the of inclination angle of the center of gravity was less than The action line it ranged between $\left[10^{\circ}: 8^{\circ}\right]$ during the take-off from the optimal angle.

The results of the dynamic force analysis, during the push phase from the traditional starting angle, also show a variation in the forces of the foot for each player separately on the horizontal and vertical planes, where higher values are given for the vertical level than the horizontal plane for the front foot, at the same time higher values are given on the horizontal than the vertical plane for the posterior foot, this indicates that the players are unable to employ the action line of the forces of the foot in the direction of the center of gravity, as the inclination angle of the center of gravity ranged from the action line the force resultant of both foot from $\left[9^{\circ}: 6.7^{\circ}\right]$ and the amount of the front foot ranged [381.9: 236.9] Newton at the vertical plane and between [34 3.9: 205.9] Newton at the horizontal plane. While the back foot, which gave the highest values on the horizontal, ranges the value of force between [202: 111] Newton at the horizontal plane, between [170.9: 89.9] Newton at the vertical plane, the researcher attributes the variation of these forces to two factors, one direct and the other indirect. The direct factor is the traditional take-off angle, which has an indirect factor, which is the larger angle of the front foot force action line at the horizontal plane, which results in this recitation between forces.

As for the results of the dynamic force analysis during the push phase from the optimum take-off angle, the researcher noted that the values of the superpower were at the horizontal plane of the front and back foot, the value of force for the front foot ranged between [473: 144.7] Newton at the horizontal plane and between [411.9: 181.9] at the vertical plane, while the back foot, which gave the highest values on the horizontal as well, ranges the value of force from [277: 112] Newton on the horizontal plane and between [171: 78] Newton at the vertical plane according to the plane of each player separately. The reason here is due to the first two factors: the optimum 
take-off angle, which results in reducing the angle of the force action line with the horizontal plane for both the front foot and the rear on from the angle of the force action line with the horizontal plane of the traditional take-off angle of the front foot with a difference ranged between $\left[-12^{\circ}:-8^{\circ}\right]$ for the rear foot the difference ranged between $\left[-9^{\circ}:-3^{\circ}\right]$ This resulted in the ability of the players to employ the reaction forces, as the forces action line of the foot got close to the center of gravity where the inclination angle of the center of gravity ranged between the force action line of the between $\left[2.5^{\circ}: 1.3^{\circ}\right]$.

In the view of the results of the dynamic analysis of the force and the inclination angle of the center of gravity from the action line of the aforementioned force of the foot, the researcher was able to arrive at the value of lost force during the traditional starting angle and the optimal angle take-off, the value of lost force ranged between the traditional take-off angle between [65.3: 29.6N] for the left foot and from [31.6: $13.9 \mathrm{~N}$ ] for the right foot While the value of lost force decreased at the starting from the optimal angle, the value ranged between [22.1: 5.2N] for the left foot and between [11.2: $2.5 \mathrm{~N}$ ] for the right foot which is a small loss compared to the take-off angle the traditional reason is due to the direct factor which is the take-off optimal angle, enabling players to employ the reaction force resultant of the of the foot to the weight of the center of gravity during the push and take-off phase.

\section{Conclusions:}

- The researcher reached to build a mathematical model through which he can analyze both the static and dynamic force of the foot force reaction action line for the starting position in the $50 \mathrm{~m}$ freestyle race.

- Through the mathematical model and the mat lab program, one of the mathematical applications, the researcher was able to calculate theoretically of the optimum take-off angle which is $\left[30^{\circ}\right]$ with the horizontal plane, by way of drawing a mathematical relationship between the take-off angle and the maximum horizontal distance that can be achieved taking into account the take-off velocity of equation No. [8] .

- The researcher was able to verify the validity of the mathematical model by conducting the practical application of the optimum take-off angle and analyzing the static and dynamic force, which showed quantitative differences when compared to the traditional angle take-off in favor of the optimum angle take-off.

- The results of the dynamic force analysis of the conventional take-off angle during the propulsion stage showed a variation in the values of force exerted at the horizontal and vertical planes of the front foot than the rear foot, as it gave the highest value of force at the vertical plane than the horizontal of the front foot and vice versa with the rear foot.

- The small angle of the inclination of the center of gravity and its proximity to the action line of the resultant of the force of the foot during the phase of propulsion and departure from the optimum angle, which resulted in the ability of the swimmers to employ the sum of the reaction force of the foot towards the center of gravity, and vice versa with the traditional take-off angle.

- The reducing in the amount of force lost at the starting point from the optimum angle. The value ranged between [22.1: $5.2 \mathrm{~N}$ ] to the left foot and between [11.2: $2.5 \mathrm{~N}$ ] to the right foot, which is a small loss compared to the traditional take-off angle. 


\section{Recommendations:}

- Applying the mathematical model using the mathematical equations that the researcher reached to analyze the static and dynamic force of similar skills, such as the low starting position in athletics with the aim of studying and understanding the mechanics of the body's work.

- The optimum take-off angle that the researcher reached with the training programs for swimmers should be entered because of its great impact on achieving the maximum horizontal distance on the one hand and adjusting the entry angle of the water on the other hand.

- Trainers should focus on the small angle between the front and rear foot force action line with the horizontal plane during the bush and take-off phase.

- The necessity of extracting the center of gravity when take-off to analyze the forces as one of the important variables to directly the degree of balance of the body, and to directly the player's use of the force of the foot, as well as the lost force through the inclination angle of the body with the action line of the resultant force.

\section{Reference :}

1- "Women's Swimming: 50m Freestyle - Results - 2008 Beijing Olympic Games," Australian Broadcast Corporation, accessed February 2, 2012, http://www.abc.net.au/olympics/2008/results/sw/womensswimming- $\quad 50 \mathrm{~m}$ freestyle.htm?result $=\mathrm{s} 31493$.

2- Murrell, D., \& Dragunas, A. (2013). A comparison of two swimming start techniques from the Omega OSB11 starting block. WURJ: Health and Natural Sciences, 3(1), 1.

3- Kazumasa Ozeki, Hiroshi Suito, and Shinji Sakurai (2018) KINEMATIC CHARACTERISTICS OF KICK START FOR ELITE COMPETITIVE JAPANESE MALE SPRINT SWIMMERS. 36th Conference of the International Society of Biomechanics in Sports.

4- Takeda, T., Takagi, H. \& Tubakimoto, S. (2009) Effect of back plate on starting block in competitive swimming. Conference for Japanese journal of Sciences in Swimming and Water Exercise 2009 Book of Abstracts.24-27.

5- Ozeki, K., Sakurai, S., Takahashi, S. \& Taguchi, M. (2014).Comparison between Kick start and Track start in the competitive swimming: Analysis of sex differences. Japanese journal of sciences in swimming and water exercise, 17(1), 4-11.

6- Bingul B, Tore O, Bulgan C, Aydin M.( 2015) The kinematic analysis of the grab, rear track, and front track start in swimming. Sport Mont (43-45): 57-62.

7- Welcher R, Hinrichs R, George T. (2008)Front- or rear-weighted track start or grab start: Which is best for female swimmers. Sports Biomech 7(1): 100-113,.

8- Nikodelis T, Kollias H.( 2003) Kinematic differences between grab and track swimming starts. Inquiries in Sport \& Physical Education.;1(1): 27-35.

9- Blanksby B, Nicholson L, Elliott B. Biomechanical analysis of the grab, track and handle swimming starts: an intervention study. Sports Biomechanics. 2002;1: 11- 24. doi: $10.1080 / 14763140208522784$.

10- El-Bahrawi, M., Krüger, T., Wick, D., \& Hohmann, A. (2002). Biomechanics of the grab and track start technique. Book of Abstracts, IXth World Symposium Biomechanics and Medicine in Swimming, 21-23 June 2002, Saint-Etienne, France, 73.

11- Alptekin, A. (2014). Body composition and kinematic analysis of the grab start in youth swimmers. Journal of human kinetics, 42(1), 15-26.

12- Slawson, S. E.; Chakravorti, N.; Conway, P. P.; Cossor, J.; West, A. A., 2012. The Effect of Knee Angle on Force Production, in Swimming Starts, using the OSB11 Block, Procedia Engineering, 34, (p. 801-806). 